\title{
Ultrastructural Characterization of Infection and Colonization of Maize Leaves by Colletotrichum graminicola, and by a C. graminicola Pathogenicity Mutant
}

\author{
C. W. Mims and L. J. Vaillancourt
}

First author: Department of Plant Pathology, Julian H. Miller Plant Sciences Building, University of Georgia, Athens 30602; and second author: Department of Plant Pathology, S-305 Agricultural Science Center-North, University of Kentucky, Lexington 40546. Accepted for publication 19 March 2002.

\section{ABSTRACT}

Mims, C. W., and Vaillancourt, L. J. 2002. Ultrastructural characterization of infection and colonization of maize leaves by Colletotrichum graminicola, and by a C. graminicola pathogenicity mutant. Phytopathology $92: 803-812$.

Observations were made of the ultrastructure of infection and colonization of leaves of a susceptible maize inbred by Colletotrichum graminicola and by a $C$. graminicola pathogenicity mutant. The mutant causes no symptoms on either maize leaves or stalks. Prior evidence suggested that it is deficient in production of signal peptidase, responsible for cleavage of signal peptides from proteins destined for transport through the endoplasmic reticulum. There was no significant difference in the process of infection or colonization by the mutant and wild-type strains up to $48 \mathrm{~h}$ after inoculation. Both the mutant and the wild type produced globose, melanized appressoria within $24 \mathrm{~h}$ after inoculation on the host surface. By $36 \mathrm{~h}$, both strains had penetrated the host epidermal cells directly. The host cells frequently formed papillae in response to appressoria, but these were not usually successful in preventing fungal ingress in either case. Penetration was followed by formation of irregularly shaped, swollen infection hyphae. Infection hyphae of both strains grew biotrophically for a relatively short time (less than $12 \mathrm{~h}$ ). One or more hyphal branches was produced from each infection hypha, and these invaded adjacent mesophyll cells. Both strains of the fungus grew cell-to-cell, setting up new biotrophic interactions in each cell, between 36 and $48 \mathrm{~h}$ after inoculation. Papillae were frequently formed by the mesophyll cells, but these were not successful in preventing fungal ingress. The first noticeable difference between the mutant and the wild type was related to their interaction with mesophyll cells. Cells invaded by the wild type died relatively quickly, whereas those infected by the mutant appeared to survive longer. The most dramatic difference between the mutant and wild type occurred when the mutant completely failed to make a transition to necrotrophic growth, while the wild type made that switch at 48 to $72 \mathrm{~h}$ after inoculation. The mutant may be unable to secrete sufficient quantities of one or more proteins that are necessary to support the switch between biotrophy and necrotrophy.

Additional keywords: corn anthracnose, corn stalk rot, Glomerella graminicola.
Anthracnose leaf blight (ALB) and anthracnose stalk rot (ASR) of maize are caused by the fungus Colletotrichum graminicola (Ces.) G. W. Wils. (teleomorph Glomerella graminicola Politis) (7). Prior to 1970, C. graminicola was considered to be only a minor pathogen of maize in North America. This perception changed after several severe epidemics of ASR occurred during the early 1970s in the north-central and eastern United States. Elimination of highly susceptible germ plasm from commercial hybrids has successfully prevented further devastating disease outbreaks. Nevertheless, anthracnose, particularly ASR, is very common in U.S. maize fields, and seed producers must remain vigilant if future epidemics are to be avoided.

Resistance to anthracnose is mostly polygenic, although a few major resistance genes have also been identified (3-5,9,17,18,36, 39). Major gene resistance is not generally used in commercial hybrids (7). We know relatively little about the specific mechanisms that mediate host resistance or fungal pathogenicity in the anthracnose disease interaction. However, a number of different physiological and biochemical responses of maize leaves to infection by $C$. graminicola have been characterized. These responses are general defensive reactions that also occur after infection by other fungal pathogens. One of the first visible responses, occurring prior to fungal penetration, is the production of lignified

Corresponding author: L. Vaillancourt; E-mail address: vaillan@uky.edu

Publication no. P-2002-0528-01R

(C) 2002 The American Phytopathological Society papillae in the outer walls of epidermal cells directly beneath appressorial cells $(8,30)$. If a papillum is formed quickly enough, and if it becomes heavily lignified, it may prevent fungal ingress. If the fungus succeeds in penetrating into the epidermal cell, the plant responds by up-regulation of genes that are involved in phenylpropanoid biosynthesis $(15,22)$. Some of the resulting compounds are converted via esterification to cell wall polymers that are more resistant to cell wall degrading enzymes produced by the fungus. Other responses include production of "stress lignin" in cells surrounding lesions, which may limit lesion expansion (37), induction of pathogenicity-related proteins including antimicrobial proteins such as chitinases (31), and production of anthocyanin pigments in a zone surrounding the lesions (15). The events that occur in reaction to stalk infection are not as well characterized as foliar responses, but they include a rapid wound-healing type of response (20,21). All of these responses are quantitative rather than qualitative, and they occur in hosts that are susceptible, as well as resistant, to ALB and ASR. Thus, the specific role of these responses in mediating resistance to $C$. graminicola is not clear.

Study of fungal mutants that are deficient in the ability to cause disease can be very informative in the dissection of host-pathogen interactions. We initiated a random mutagenesis study to identify pathogenicity mutants of $C$. graminicola using a restriction enzyme-mediated insertional (REMI) mutagenesis approach (35). One of the mutants that emerged from that study has been characterized in some detail. It contains a mutation in a gene that is predicted to encode one component of the microsomal signal peptidase enzyme, and it causes no symptoms on either leaves or 
stalks of maize $(34,35)$. Our preliminary light microscopy studies suggested that this mutant was affected in postpenetration events (34). In the present study we had two objectives: first, to describe the ultrastructure of pathogen development and host responses in the wild-type ALB disease interaction, something that has not been done before; and second, to compare the mutant interaction with the wild type in detail.

\section{MATERIALS AND METHODS}

Preparation of infected tissues. The wild-type strain used in this study was M1.001, which was recovered from diseased corn in the United States in the early 1970s (isolate 2, described in literature citations 14 and 24). The mutant strain was derived from M1.001 by REMI mutagenesis (35). Both strains of $C$. graminicola were cultured on potato dextrose agar (PDA) (Difco Laboratories, Detroit) plates under continuous fluorescent light at 22 to $25^{\circ} \mathrm{C}$. Falcate conidia from 14- to 21 -day-old cultures were used to inoculate plants. The conidia were taken directly from the cultures by lightly rubbing the colony surface with a sterile cotton swab. The conidia were then applied to the upper surfaces of the youngest fully expanded leaves of 2- to 3-week-old maize seedlings in the greenhouse according to a modified procedure of Sweigard et al. (33), in which gelatin was not included as a carrier for the spores. Inbred Mo940, which is highly susceptible to ALB, was the host (23). Inoculated plants were placed in a darkened misting chamber for at least $14 \mathrm{~h}$ at 29 to $35^{\circ} \mathrm{C}$ and then returned to the greenhouse bench. Our simple, but effective, misting chamber consists of a room humidifier operating continuously inside a wooden frame covered with plastic sheeting. It does not have temperature controls.
Isolation of fungus from infected tissues. Maize leaves inoculated with either the wild type or mutant strain of $C$. graminicola were collected 21 days after inoculation. Three inoculated leaves from each treatment were surface-sterilized by soaking them in $10 \%$ bleach containing $0.1 \%$ Tween 20 for $10 \mathrm{~min}$ and then rinsing in three changes of sterile deionized water. Each leaf was cut with a scalpel into slices approximately $1 \mathrm{~cm}$ wide, and the pieces were placed on PDA plates and incubated for up to 5 days. This experiment was repeated twice.

Fixation and preparation of inoculated leaf samples. At various times after inoculation, beginning at $24 \mathrm{~h}$, a razor blade was used to cut small pieces from the inoculated leaves approximately midway between the leaf base and the leaf tip, and closer to the midrib than the leaf edge (microscopic examination revealed that the majority of germinating conidia were located here, perhaps carried by the water droplets that accumulated on the leaves in the misting chamber). Samples consisting of $1-$ to $2-\mathrm{mm}^{2}$ fragments of inoculated leaves were fixed for 2 days at $4{ }^{\circ} \mathrm{C}$ in $2.5 \%$ glutaraldehyde in $100 \mathrm{mM}$ phosphate buffer at $\mathrm{pH} 6.8$. Samples were postfixed in similarly buffered $1 \%$ OsO for $2 \mathrm{~h}$ at $4^{\circ} \mathrm{C}$, rinsed in multiple changes of distilled water, and stained overnight in aqueous uranyl acetate.

Electron and light microscopy. Following a water wash, samples for scanning electron microscopy (SEM) were critical point dried, mounted on specimen stubs, and coated with gold prior to examination with a scanning electron microscope (JEOL 5800; JEOL, Akishima, Japan) operating at $15 \mathrm{kV}$.

Samples for transmission electron microscopy (TEM) were dehydrated in a graded ethanol series, infiltrated with Spurr's resin, and placed in disposable tissue culture dishes (Lux Contur Permanox, VWR Scientific Products, Bridgeport, NJ) containing fresh
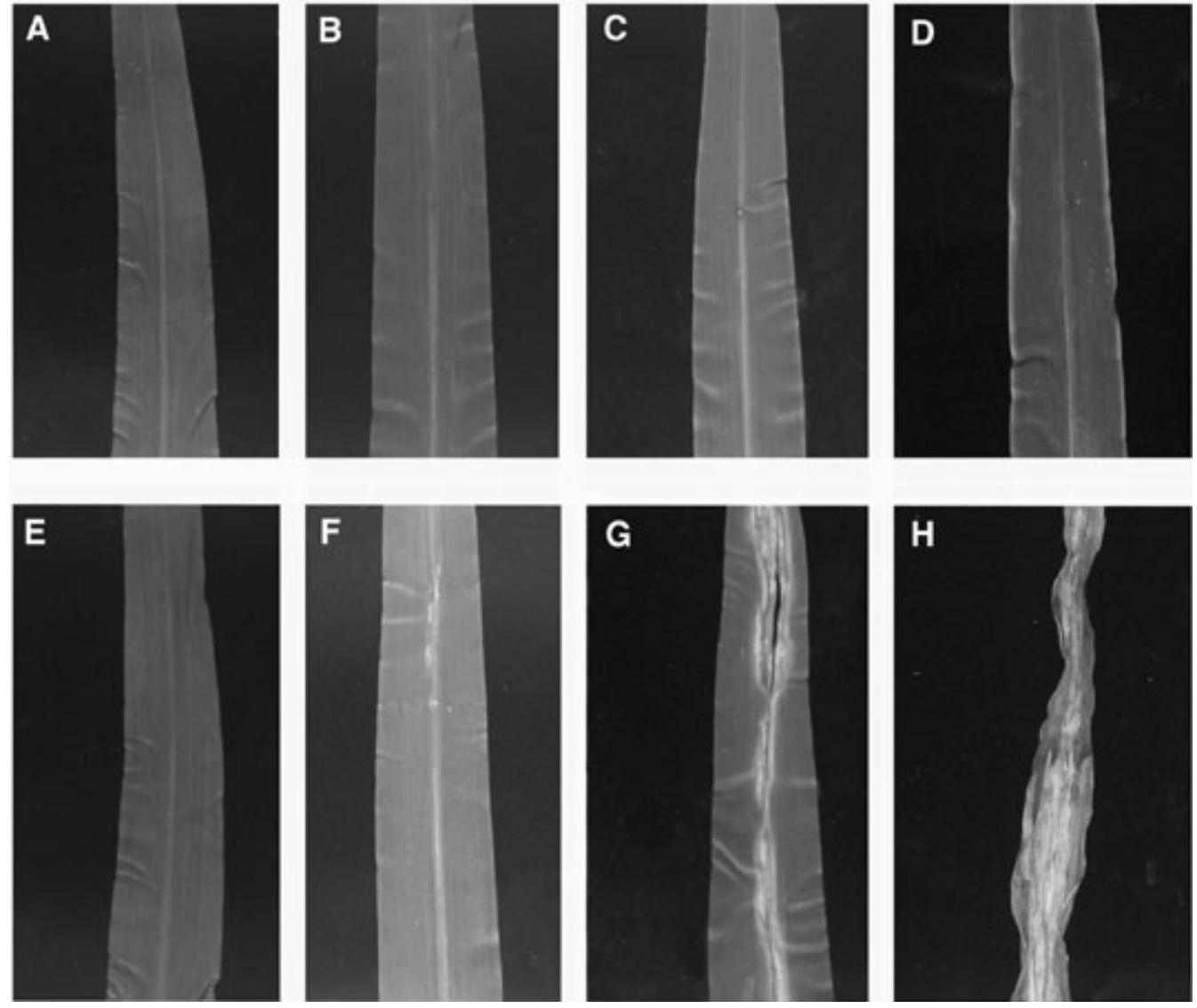

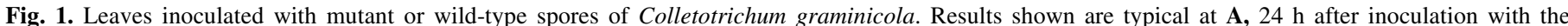

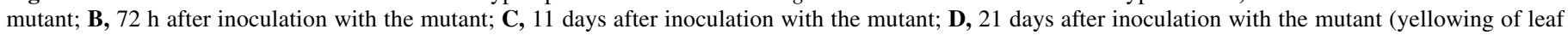

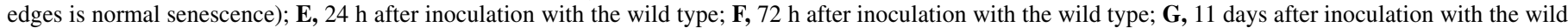
type; and $\mathbf{H}, 21$ days after inoculation with the wild type. 
$100 \%$ resin. Following polymerization of the resin, the bulk embedded samples were removed from the culture dishes and placed on the stage of a light microscope, which was used to locate and orient fungal structures in or on leaves for sectioning (19). Because the appressoria were melanized, it was relatively easy to find these structures on the surfaces of fixed and embedded leaf samples. This greatly facilitated efforts to obtain sections through infection sites for study. Thin sections for TEM were cut with a diamond knife, collected on slot grids, and allowed to dry onto formvar-coated aluminum racks according to the procedure of Rowley and Moran (29). Sections were post-stained with uranyl acetate and lead citrate prior to examination with a microscope (Zeiss 902A; Zeiss, Oberkochen, Germany) operating at $80 \mathrm{kV}$. At least 20 representative infection sites were sectioned for each treatment at each time point.

For light microscopy, 1- $\mu$ m-thick sections of resin embedded samples were stained with toluidine blue $\mathrm{O}$ and examined and photographed with bright field optics.

Immunogold labeling. Gold labeling of callose in plant cells was accomplished by a polyclonal antibody that recognizes $(1 \rightarrow 3)$ - $\beta$-glucans $(25)$. The procedures and controls used for gold labeling were identical to those described by Enkerli et al. (13).

\section{RESULTS}

Macroscopic symptom development. The $C$. graminicola mutant caused no macroscopic symptoms on leaves, even up to 3 weeks after inoculation, whereas leaves inoculated with the wild-type strain began to exhibit symptoms only 3 days after inoculation (Fig. 1). Leaf pieces were plated on culture medium 21 days after inoculation with either the mutant or wild-type strains. The mutant fungus did not grow from the leaves prior to 3 days after plating, and it emerged from only $27 \%( \pm 4.2 \%)$ of the leaf pieces within 5 days. In contrast, the wild-type strain grew from $95 \%( \pm 6.4 \%)$ of the tissue pieces within 1 day of being cultured.

SEM and light microscopy. By $24 \mathrm{~h}$ postinoculation (hpi), conidia of both the wild type and mutant strains of $C$. graminicola had germinated at apparently equal rates, and each conidium had given rise to a single germ tube, at the tip of which the appressorium was formed. Germ tube length and appressorium morphology were variable in both strains, but observation with either light microscopy or SEM revealed no consistent differences between the appressoria of the two strains (Fig. 2A to C).

Light microscopic examination of $1-\mu \mathrm{m}$-thick sections of inoculated leaves revealed no evidence of epidermal cell penetration by either the wild type or the mutant at 24 hpi. However, papillae (Fig. 3A) were easily observed in epidermal cells immediately beneath the appressoria of both strains.

By 36 hpi, some of the papillae had become very large, as illustrated in Figure 3B. There was, however, no consistent difference in the size or number of papillae produced in response to the wildtype versus mutant strains. In spite of a very obvious host defensive response, penetration of epidermal cells by both strains had occurred, and well-developed hyphae were observed within the epidermal cells (Fig. 3C). In some cases, hyphae of both strains had also begun to enter the first layer of mesophyll cells, and papillae were evident at these secondary penetration sites (Fig. 3D).

By 48 hpi, hyphae of both the wild type and the mutant were well established within the leaf mesophyll. Necrosis of individual invaded mesophyll cells was evident in leaves infected by both strains, but cell death was more common in leaves infected by the wild-type strain (Fig. 3E and F). Encapsulation of invading hyphae of both strains by an irregular coat of wall apposition material was observed in some cells (Fig. 3E).

By 72 hpi, wild-type infection sites were characterized by extensive host cell death, large numbers of secondary infection hyphae within and between cells, and the complete collapse of large areas of leaf tissue (Fig. 3G). It is at this time that macroscopic lesions begin to be observed on leaves infected by the wild type (Fig. 1). In contrast, only a few dead cells could be found in leaves infected by the mutant strain at $72 \mathrm{hpi}$, and no large-scale collapse of leaf tissue was evident (Fig. 3H). However, in spite of the absence of disease symptoms, hyphae of the mutant strain were present in infected leaves at 72 hpi (Fig. 3H). Most of these hyphae were located in what appeared to be intact, non-necrotic cells. Hyphae were particularly common within bundle sheath cells (Fig. 3H).

TEM. TEM confirmed our light microscopic observations and provided important additional information regarding details of the host-pathogen interaction between the wild-type and the mutant strains of $C$. graminicola and maize leaf cells. The internal structure of appressoria at 24 hpi was not clear, because the quality of
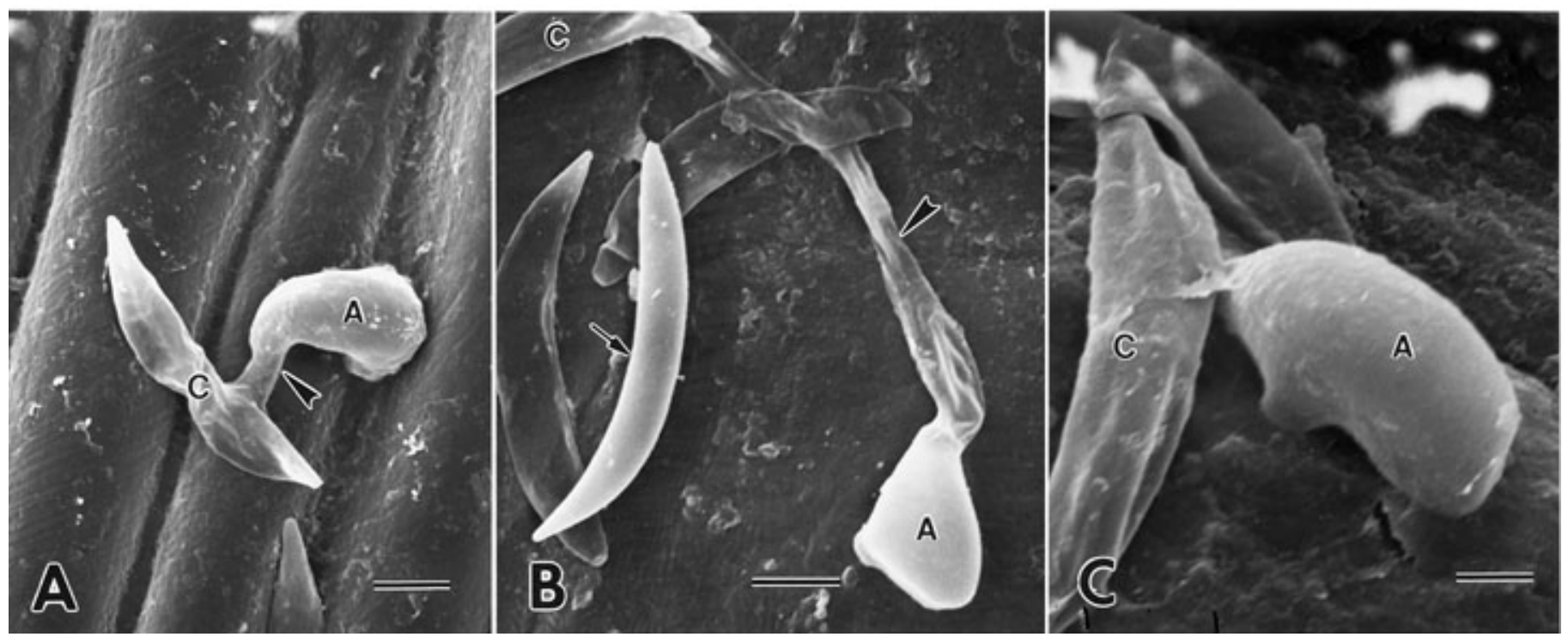

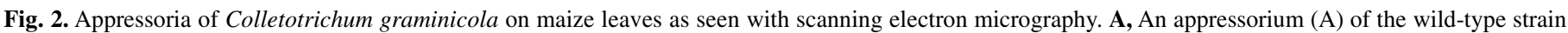

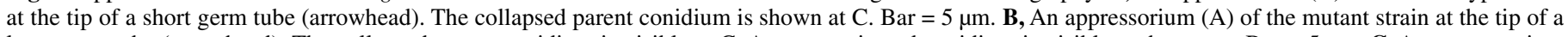

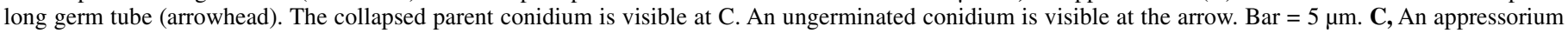
(A) of the mutant strain in virtual contact with the parent conidium (C). Bar $=2.5 \mu \mathrm{m}$. 
fixation of these melanized structures was not particularly good. However, we were able to confirm that appressoria of $C$. graminicola do not possess the appressorial cone structure that is seen in some other species of Colletotrichum $(6,26,28)$. The inner, electron-lucent wall at the base of the appressorium, originally described by Politis and Wheeler (28), was evident in our sections
(Fig. 4A). Papillae were formed between the host plasmalemma and the host cell wall of epidermal cells in response to appressoria of both strains of the fungus. The papillae exhibited positive labeling for callose (Fig. 4B). As already noted, some of these papillae eventually became quite large and appeared to prevent host cell penetration by both strains at some sites (Fig. 4C and D). There

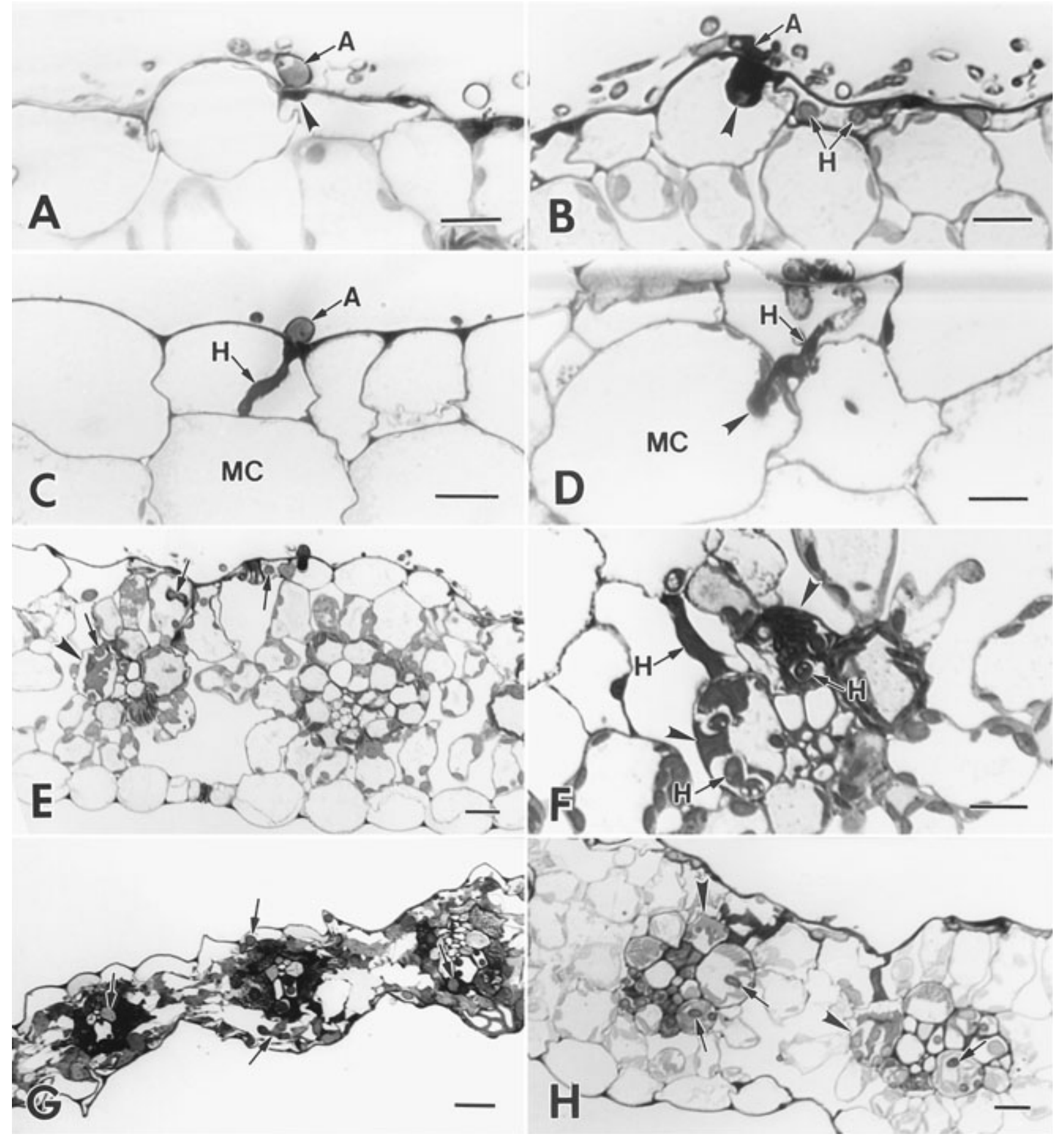

Fig. 3. Wild type and mutant strains of Colletotrichum graminicola on maize leaves. Light micrographs of sections (1 $\mu \mathrm{m}$ thick) of resin embedded samples stained with toluidine blue O. A, An appressorium (arrow) of the mutant strain on a leaf at $24 \mathrm{~h}$ postinoculation (hpi). A small papilla (arrowhead) is visible in the epidermal cell immediately beneath the appressorium. B, A very large papilla formed in response to an appressorium (A) of the wild-type strain at 48 hpi. It is important to emphasize that equally large papillae were sometimes formed in response to the mutant strain. Hyphae $(\mathrm{H})$ are visible in the epidermal cell to the right of the cell containing the papilla. C, An appressorium (A) with a hypha $(\mathrm{H})$ of the mutant strain extending through an epidermal cell to contact a mesophyll cell (MC) at 36 hpi. D, Hypha (H) of a wild-type strain extending through an epidermal cell and into an MC at 36 hpi. The hypha in the MC appears to be completely encased in wall apposition material (arrow). Similar material was also sometimes deposited around hyphae of the mutant strain. E, Section of a leaf infected by the wild-type strain at $48 \mathrm{hpi}$. A few hyphae are visible at the arrows and a necrotic host cell at the arrowhead. F, Higher magnification view of a portion of a host leaf infected by the wild-type strain at 48 hpi. Hyphae are visible at $\mathrm{H}$ and necrotic host cells at the arrowheads. G, Portion of a leaf infected by the wild-type strain at 72 hpi. Note the collapsed nature of the leaf. Numerous hyphae (arrows) are visible within and between the leaf cells. H, Portion of a leaf infected by the mutant strain at $72 \mathrm{hpi}$. A few necrotic host cells are visible (arrowheads) but the leaf is not collapsed, and hyphae (arrows) are evident in apparently intact, non-necrotic bundle sheath cells. Bars $=10 \mu \mathrm{m}$. 


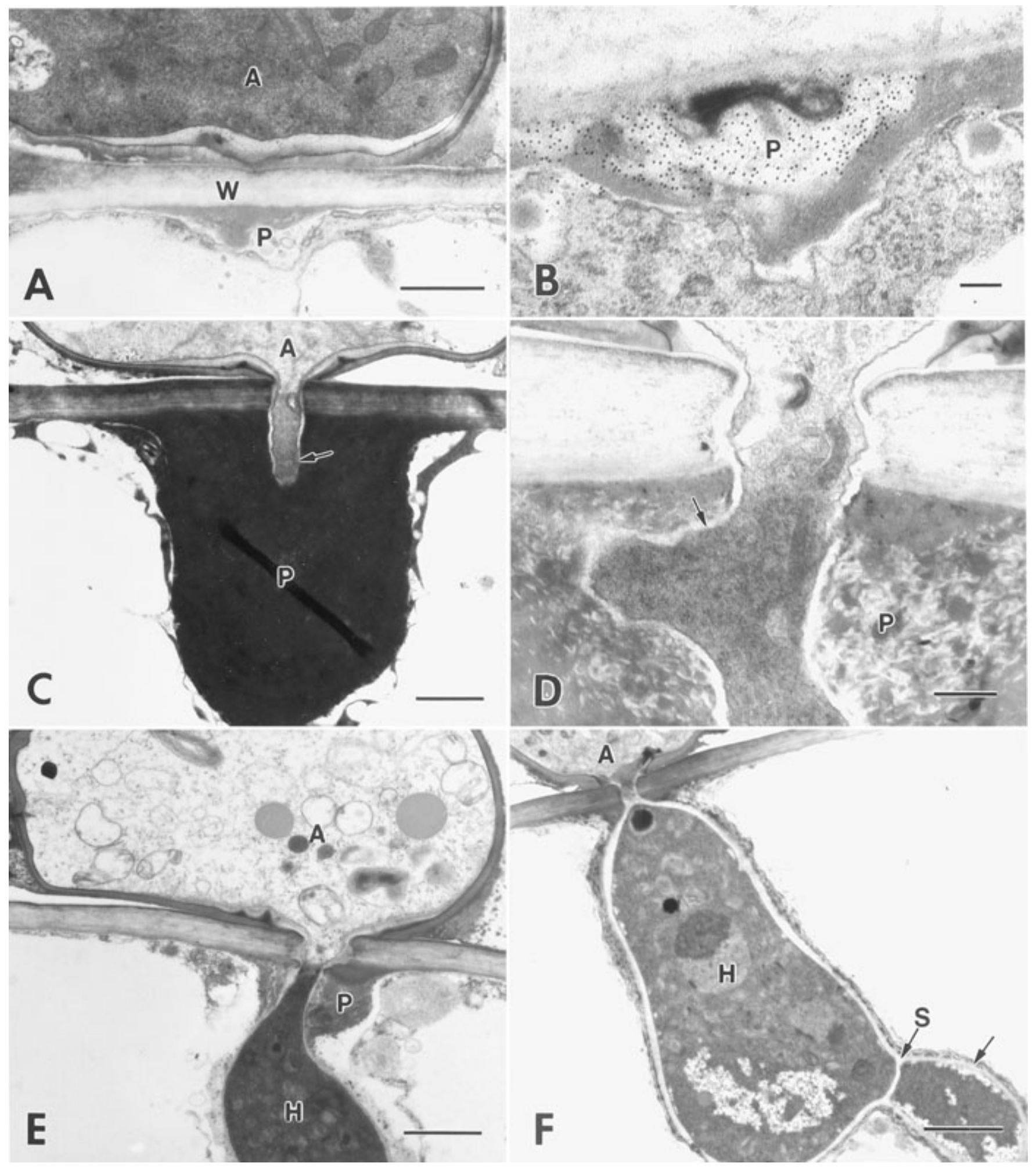

Fig. 4. Transmission electron micrographs of the interactions of the wild type and mutant strains of Colletotrichum graminicola with maize leaf cells. Infection processes were apparently identical, and images included here were chosen to be representative of both strains. A, Portion of a papilla (P) in an epidermal cell beneath an appressorium (A) of the mutant strain at $24 \mathrm{~h}$ postinoculation (hpi). The wall of the epidermal cell is visible at W. Note the electron-lucent zone at the base of the appressorium. Bar $=1 \mu \mathrm{m}$. B, Gold labeling for callose in a papilla formed in an epidermal cell in response to the wild-type strain at 24 hpi. Bar $=$ $0.4 \mu \mathrm{m}$. C, Very large and dense papilla (P) in an epidermal cell at $48 \mathrm{hpi}$. An apparently unsuccessful penetration peg (arrow) from the appressorium (A) of a wild-type strain is visible in the papilla. Papillae were usually not successful in blocking ingress of either the mutant or the wild-type strain. Bar $=1.5 \mu \mathrm{m}$. D, Example of a branched and apparently necrotic penetration peg (arrow) of the mutant strain in an epidermal cell papilla $(\mathrm{P})$ at $48 \mathrm{hpi}$. Bar $=0.5 \mu \mathrm{m}$. E, Portion of a slightly swollen hypha $(\mathrm{H})$ of the wild-type strain in an epidermal cell at $36 \mathrm{hpi}$. The parent appressorium is visible at A and the host cell papilla at P. The hypha appears to be necrotic, and the host cytoplasm and plasma membrane seem to be disorganized. Bar $=2 \mu \mathrm{m}$. F, Portion of a swollen hypha $(\mathrm{H})$ of the mutant strain in an epidermal cell at $36 \mathrm{hpi}$. A branch (arrow) has arisen from the swollen hyphae just distal to a septum (S). A portion of the parent appressorium is visible at A. Note the host wall appositions forming a collar around the penetration peg where it enters the host cell. Bar $=2 \mu \mathrm{m}$. 
was no consistent difference in the size or number of papillae produced in response to appressoria of either strain. In most of the penetration sites we examined, papillae were not successful in preventing invasion of epidermal cells by either strain of the fungus. Typically a penetration peg arose from the underside of each appressorium and penetrated the host cell wall and the associated papilla. There was no significant deformation of the host wall, although the cuticle layer did appear to be slightly compressed by the emerging penetration peg (Fig. 4A and D). An electron-lucent zone, which appeared to be continuous with the inner electronlucent wall of the appressorium, could be seen around the penetration peg (Fig. 4C and D). By 36 hpi, the tip of the peg had usually expanded to form a swollen, irregularly shaped primary infection hypha within the invaded epidermal cell (Fig. 4E and F). Frequently one or more hyphal branches had already arisen from the primary hypha and either contacted or actually entered the first layer of mesophyll cells (Fig. 5A). Mesophyll cells typically formed papillae in response to the hyphae of both strains of the fungus (Fig. 5A and B) but again, the development of these structures did not appear to be very successful in preventing the spread of hyphae within infected leaves.

By 36 hpi, many of the epidermal cells invaded by both strains of the fungus already appeared to be necrotic (Fig. 5A to C). However, the presence of electron-lucent wall-apposition material (Fig. 5C) around hyphal elements of both strains of the fungus indicated that the invaded epidermal cells were alive for at least a short time following their penetration. These wall appositions also exhibited callose labeling (Fig. 5D). TEM confirmed some mesophyll cell necrosis in response to the wild-type strain at $36 \mathrm{hpi} \mathrm{(Fig.} \mathrm{5E)} \mathrm{and}$ even more cell death at 48 hpi. Mesophyll cell death in response to the mutant strain was less common at these time points.

TEM of leaves infected by the wild-type strain at $48 \mathrm{hpi}$, and particularly at $72 \mathrm{hpi}$, was relatively uninformative, except to confirm the presence of a large number of well-developed secondary hyphae in and between mostly dead host cells (Fig. 5F). On the other hand, examination of leaves infected by the mutant strain at 72 hpi proved to be very interesting. Although some evidence of necrotic mesophyll cells was apparent at this time period (Fig. 6A and B), many hyphae were also observed in intact cells that exhibited no evidence of necrosis. This was particularly true for bundle sheath cells (Fig. 6C to F). Although some hyphae of the mutant strain (Fig. 6E) were encased by host cell wall appositions similar to those found around the hyphae in epidermal cells (Fig. 5C), most appeared to be separated from the host cell cytoplasm only by the host cell plasma membrane (Fig. 5E). The intact host plasma membrane had a "ruffled" appearance reminiscent of descriptions of the haustoria of obligate pathogens (16). However, unlike haustoria, there was no extensive matrix between the host plasma membrane and the hyphal cell wall, which appeared to be in direct contact in many places. Organelles in these invaded cells appeared to be completely normal (Fig. 5C and D).

\section{DISCUSSION}

There have been no previous ultrastructural analyses of postpenetration events during infection of maize by $C$. graminicola, although an earlier paper by Politis and Wheeler (28) examined penetration of detached, highly susceptible sweet corn leaves. These workers found that penetration occurred within $12 \mathrm{~h}$, but in our studies it occurred later, at some point between 24 and $36 \mathrm{~h}$. This difference could be due to several factors, including variation in incubation temperature or humidity, the use of detached leaves versus intact plants, or differences in aggressiveness of the isolates or susceptibility of the host. Other than the difference in timing, the initial penetration events that we observed were similar to those previously reported. In the appressoria of many species of Colletotrichum, including the bean anthracnose pathogen $C$. lindemuthianum, the point of penetration peg emergence is surrounded by a structure known as the appressorial cone $(6,26)$. Our observations confirm the report of Politis and Wheeler (28) that the appressoria of $C$. graminicola do not have an appressorial cone. Instead, the structure of $C$. graminicola appressoria is very similar to that described for the closely related sorghum anthracnose pathogen, C. sublineolum (40). It is not clear whether this difference in structure represents a difference in infection strategy between the two groups of pathogens.

Papillae were commonly produced by maize epidermal cells in response to $C$. graminicola appressoria. Papillae were also produced by mesophyll cells in response to attempted hyphal invasion from neighboring cells. Papillae in either epidermal or mesophyll cells were not usually successful in preventing hyphae from entering cells. The absence of any compression or deformation of the host cell wall as the hyphae passed through the papillae suggests that the fungus is able to degrade them enzymatically, rather than relying solely on physical force.

Politis and Wheeler (28) reported that the primary infection hyphae of $C$. graminicola did not immediately breach the host plasma membrane upon entering an epidermal cell; instead, the plasma membrane remained intact and became deeply invaginated around the hypha. This suggests that $C$. graminicola is initially biotrophic. Bergstrom and Nicholson (7) also suggested that $C$. graminicola does have a short biotrophic phase, based on the fact that symptoms do not appear until a day or two after infection, but the presence of biotrophy in $C$. graminicola was questioned by O'Connell et al. (26). Our work confirms that $C$. graminicola does indeed have a biotrophic phase. Only living cells could have deposited the wall appositions we observed around hyphae within epidermal cells at 36 hpi. However, this phase appears to be very short, a period less than $12 \mathrm{~h}$ (the amount of time between when we first observed penetration and when we began to observe epidermal cell death). By the time the epidermal cell dies, the fungus has moved on to establish a new biotrophic infection in an adjacent cell. This cell-to-cell progression is very similar to what has been described for $C$. sublineolum on sorghum (40) and $C$. lindemuthianum on bean (26).

Callose-containing wall appositions were frequently formed around hyphae within epidermal and mesophyll cells. Nondevelopmental callose production in plants is often associated with defense responses against fungal and oomycete pathogens (1). It has been suggested that these callose deposits may physically impede fungal growth or block nutrient transfer from host to pathogen (2). It is also possible that they serve as a medium for deposition of toxic compounds (1). It was difficult to tell whether the appositions were effective in preventing further development of individual hyphae, but in the case of the wild-type strain, they were clearly unable to prevent the fungus from eventually killing the entire inoculated leaf (Fig. 1).

Between 48 and 72 hpi, the wild-type fungus underwent a dramatic shift in behavior as it made the transition from mostly biotrophic growth to necrotrophy. It is only during the necrotrophic phase of the Colletotrichum disease cycle that anthracnose lesions appear. Necrotrophic growth of $C$. graminicola was characterized by the production of large numbers of invasive hyphae that grew extensively throughout the host cells, within cell walls, and throughout the intercellular spaces. Host tissues were completely destroyed, even ahead of actual fungal colonization. Necrotrophic growth of $C$. graminicola on maize was very similar to the necrotrophic growth phase of $C$. sublineolum on sorghum (40), which is also typical of the necrotrophic growth phases of most other $\mathrm{Col}$ letotrichum fungi $(6,26)$.

The behavior of the $C$. graminicola pathogenicity mutant was very interesting. The sequence of events involved in penetration and initial infection seemed to be the same in the mutant and wildtype strains. Appressoria that were apparently identical were formed at equivalent rates, and both strains seemed to be equally capable of penetrating host cells and overcoming papillae. Invaded epider- 
mal cells were killed by both strains relatively quickly. The first noticeable difference was related to the interaction with mesophyll cells. Mesophyll cells invaded by the wild type died rather quickly, whereas mesophyll cells infected by the mutant appeared to survive longer. Because they persisted longer, it was much easier to observe biotrophic hyphae of the mutant strain in host mesophyll cells. The most dramatic difference between the mutant and wild type occurred when the mutant completely failed to make a transi-
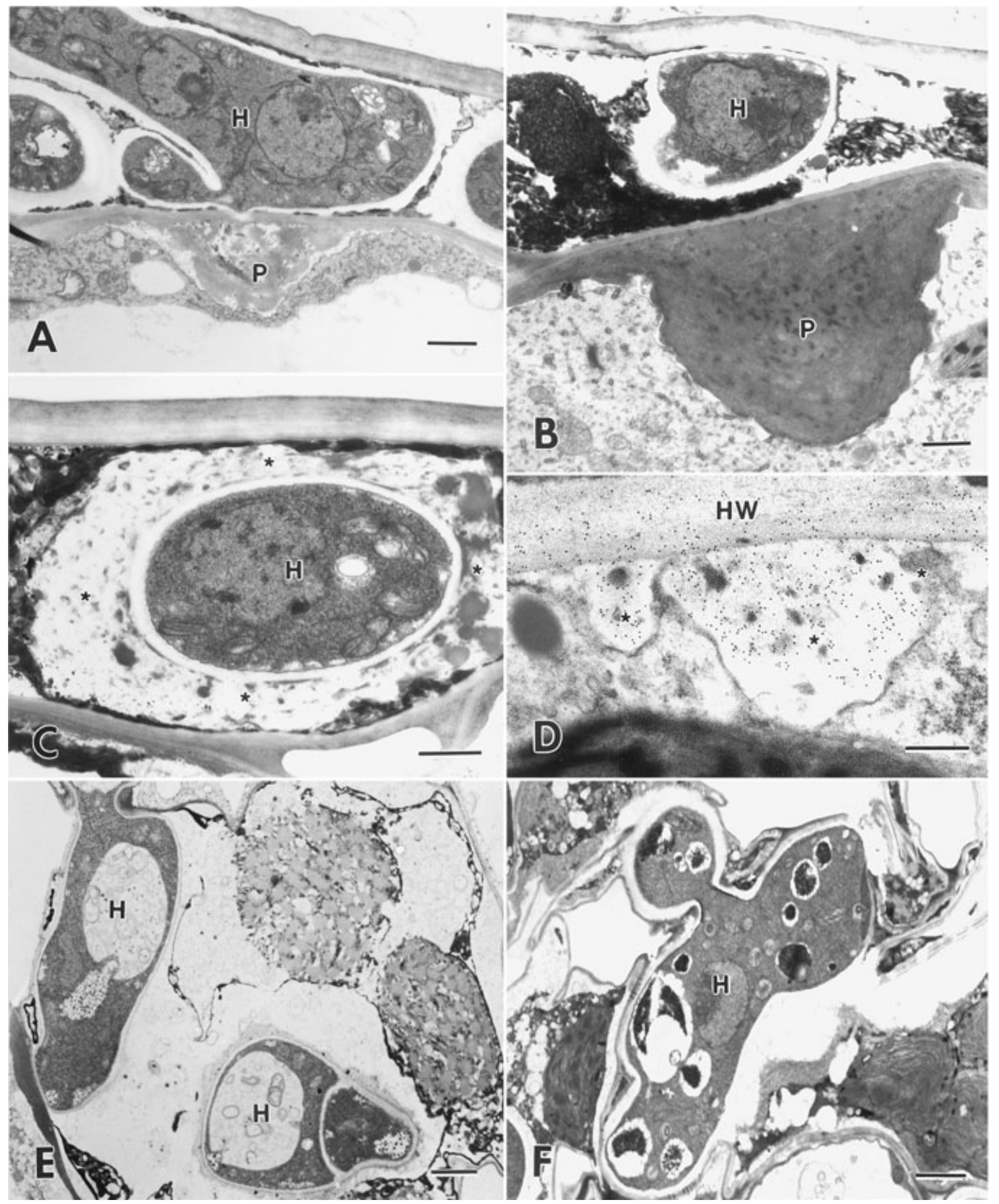

Fig. 5. Transmission electron micrographs of maize leaf cells infected by the wild type and mutant strains of Colletotrichum graminicola. A, Hypha (H) of the wild-type strain in an epidermal cell at $36 \mathrm{~h}$ postinoculation (hpi). Note the papilla $(\mathrm{P})$ in the underlying mesophyll cell. Bar $=1 \mu \mathrm{m}$. B, Hypha $(\mathrm{H})$ of the mutant strain in an obviously necrotic, collapsed epidermal cell at 36 hpi. Note the very large papilla $(\mathrm{P})$ in the underlying mesophyll cell. Bar $=1 \mu \mathrm{m}$. $\mathbf{C}$, Cross section of a hypha $(\mathrm{H})$ of the wild-type strain in a necrotic epidermal cell at 36 hpi. Note the wall apposition (asterisks) that completely surrounds the hypha. Bar $=1 \mu \mathrm{m}$. D, Gold labeling of callose in the wall apposition (asterisks) surrounding a hypha of the mutant strain in an epidermal cell at 36 hpi. The hyphal wall is also labeled due to the presence of $(1 \rightarrow 3)-\beta$-glucans. Bar $=0.2 \mu \mathrm{m}$. $\mathbf{E}$, Hyphae $(\mathrm{H})$ of the wild-type strain in a mesophyll cell at $36 \mathrm{hpi}$. Bar $=1 \mu \mathrm{m}$. $\mathbf{F}$, Hypha $(\mathrm{H})$ of the wild-type strain surrounded by dead mesophyll cells at $72 \mathrm{hpi}$. Bar $=1 \mu \mathrm{m}$. 

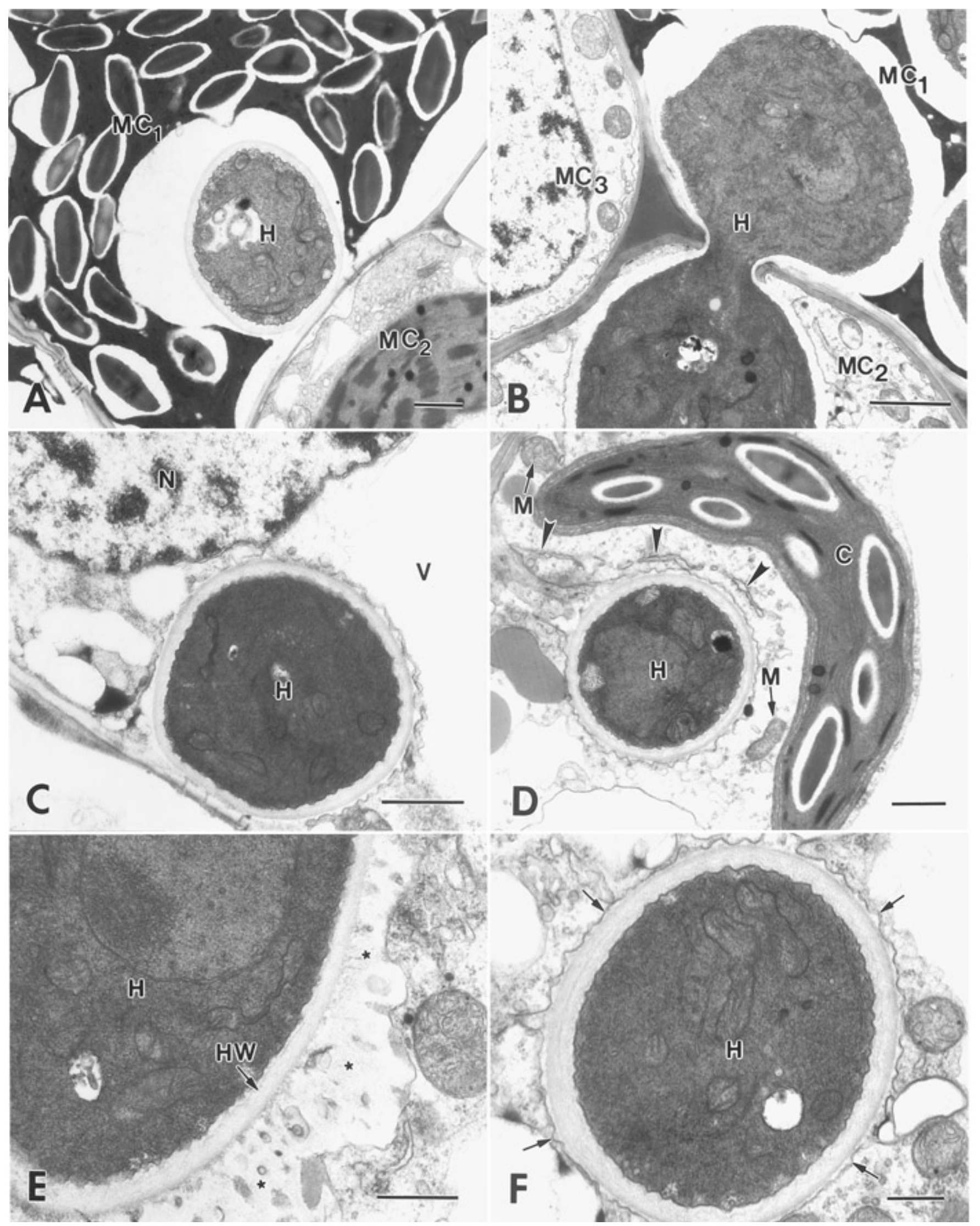

Fig. 6. Transmission electron micrographs of maize leaf cells infected by the mutant strain of Colletotrichum graminicola at $72 \mathrm{~h}$ postinoculation (compare with Figure 5F). A, Cross section of a hypha $(\mathrm{H})$ in a necrotic mesophyll cell $\left(\mathrm{MC}_{1}\right)$. A portion of an intact $\mathrm{MC}$ is shown at $\mathrm{MC}_{2}$. Bar $=1 \mu \mathrm{m} . \mathbf{B}, \mathrm{Hypha}(\mathrm{H})$ extending from a necrotic mesophyll cell $\left(\mathrm{MC}_{1}\right)$ into an intact mesophyll cell $\left(\mathrm{MC}_{2}\right)$. A portion of another intact cell is shown at $\mathrm{MC}_{3}$. Bar $=1 \mu \mathrm{m}$. $\mathbf{C}$ and $\mathbf{D}$, Cross sections of hyphae $(\mathrm{H})$ in intact bundle sheath cells. Portions of a host cell nucleus $(\mathrm{N})$ and vacuole $(\mathrm{V})$ are visible as well as a chloroplast $(\mathrm{C})$, mitochondria $(\mathrm{M})$, and strands of rough endoplasmic reticulum (arrowheads). Bars $=1 \mu \mathrm{m}$. E, Example of a wall apposition (asterisks) surrounding a hypha (H) in an intact bundle sheath cell. The hyphal wall is shown at HW. Bar $=0.5 \mu \mathrm{m}$. F, Cross section of a hypha $(\mathrm{H})$ in an intact bundle sheath cell. The hypha is separated from the host cytoplasm only by the host cell plasma membrane (arrows). Bar $=0.5 \mu \mathrm{m}$. 
tion to necrotrophic growth, whereas the wild-type strain made that switch between 48 and 72 hpi. Because macroscopic symptoms never develop on leaves inoculated with the mutant, we suggest that the mutant never makes the transition to necrotrophy. Nonetheless, the mutant persists within the asymptomatic leaves up to 3 weeks after inoculation, although the fungal biomass within the tissue appears to be significantly reduced in comparison with the wild-type strain.

The causes and mechanisms of the transition from biotrophy to necrotrophy remain mysterious in the hemibiotrophic Colletotrichum fungi. A few genes have been identified that play roles in this transition. These include a $C$. lindemuthianum zinc-finger transcription factor (12), a protein of unknown function that localizes to the surfaces of biotrophic hyphae of $C$. lindemuthianum (27), and a secreted $C$. gloeosporioides protein that appears to suppress an hypersensitive resistance-like response in host cells (32). Whether homologues of any of these genes are affected in the $C$. graminicola pathogenicity mutant remains to be seen. At this point, we can only speculate as to the causes for the fascinating behavior of this mutant. Our available evidence suggests that the mutant is deficient in production of one component of the signal peptidase enzyme, which is responsible for cleavage of signal peptides from proteins destined for transport through the endoplasmic reticulum membrane (34). Our current hypothesis is that the mutant is unable to secrete sufficient quantities of one or more proteins that are necessary to support the switch between biotrophy and necrotrophy. One likely candidate for these secreted proteins is cell wall degrading enzymes. Secretion of various pectolytic enzymes by $C$. lindemuthianum and $C$. gloeosporioides is dramatically increased during necrotrophic growth $(10,11,38$, 41). Clearly, the mutant can produce enough degradative enzymes to penetrate the host plant and establish the initial biotrophic interaction, but greater quantities of these enzymes may be required for necrotrophic growth. This mutant will provide us with an extremely powerful tool to investigate the causes and mechanisms of the transition from biotrophy to necrotrophy, which may in turn allow us to address fundamental questions about the relationships between fungal colonization, host response, and plant disease.

\section{ACKNOWLEDGMENTS}

This work was supported in part by NRI grant 97-35303-4968 to the second author from the U.S. Department of Agriculture. We thank C. Rodrigues-Lother, E. Nuckles, and D. Brown for their excellent technical assistance; M. Thon, R. Nicholson, and R. Hammerschmidt for helpful discussions; and T. Pirone for critical reading of the manuscript. This is paper 02-12-88 from the Kentucky Agricultural Experiment Station, published with the permission of the director.

\section{LITERATURE CITED}

1. Aist, J. R. 1976. Papillae and related wound plugs of plant cells. Annu. Rev. Phytopathol. 14:145-163.

2. Allen, F., and Friend, J. 1983. Resistance of potato tubers to infection by Phytophthora infestans: A structural study of haustorial development. Plant Pathol. 22:285-292.

3. Badu-Apraku, B., Gracen, V. E., and Bergstrom, G. C. 1987. A major gene for resistance to anthracnose stalk rot in maize. Phytopathology 77:957-959.

4. Badu-Apraku, B., Gracen, V. E., and Bergstrom, G. C. 1987. A major gene for resistance to anthracnose leaf blight in maize. Plant Breed. 98:194-199.

5. Badu-Apraku, B., Gracen, V. E., and Bergstrom, G. C. 1987. Inheritance of resistance to anthracnose stalk rot and leaf blight in a maize inbred derived from a temperate by tropical germplasm combination. Maydica 32:221-237.

6. Bailey, J. A., O'Connell, R. J., Pring, R. J., and Nash, C. 1992. Infection strategies of Colletotrichum species. Pages 88-120 in: Colletotrichum: Biology, Pathology, and Control. J. A. Bailey and M. J. Jeger, eds. CAB International, Wallingford, UK.

7. Bergstrom, G. C., and Nicholson, R. L. 1999. The biology of corn anthracnose. Plant Dis. 85:596-608.
8. Cadena-Gomez, G., and Nicholson, R. L. 1987. Papilla formation and associated peroxidase activity: A non-specific response to attempted fungal penetration of maize. Physiol. Mol. Plant Pathol. 31:51-67.

9. Carson, M. L., and Hooker, A. L. 1981. Inheritance of resistance to anthracnose leaf blight in five inbred lines of corn. Phytopathology 71:488-491.

10. Centis, S., Dumas, B., Fournier, J., Marolda, M., and Esquerre-Tugaye, M.-T. 1996. Isolation and sequence analysis of CLPG1: A gene coding for an endopolygalacturonase of the phytopathogenic fungus Colletotrichum lindemuthianum. Gene 170:125-129.

11. Centis, S., Guillas, I., Sejalon, N., Esquerre-Tugaye, M.-T., and Dumas, B. 1997. Endopolygalacturonase genes from Colletotrichum lindemuthianum. Cloning of $C L P G 2$ and comparison of its expression to that of $C L P G 1$ during saprophytic and parasitic growth of the fungus. Mol. Plant-Microbe Interact. 10:769-775.

12. Dufresne, M., Perfect, S., Pellier, A.-L., Bailey, J. A., and Langin, T. 2000. A GAL4-like protein is involved in the switch between biotrophic and necrotrophic phases of the infection process of Colletotrichum lindemuthianum on common bean. Plant Cell 12:1579-1589.

13. Enkerli, K., Hahn, M. G., and Mims, C. W. 1997. Immunogold labeling of callose and other plant wall components in soybean roots infected with the oomycete Phytophthora sojae. Can. J. Bot. 75:1509-1517.

14. Forgey, W. M., Blanco, M. H., and Loegering, W. Q. 1978. Differences in pathological capabilities and host specificity of Colletotrichum graminicola on Zea mays. Plant Dis. Rep. 62:573-576.

15. Hammerschmidt, R., and Nicholson, R. L. 1977. Resistance of maize to anthracnose: Changes in host phenols and pigments. Phytopathology 67: 251-258.

16. Ingram, D. S., Sargent, J. A., and Tommerup, I. C. 1976. Structural aspects of infection by biotrophic fungi. Pages 43-77 in: Biochemical Aspects of Plant-Parasite Relationships. J. Friend and D. R. Threlfall, eds. Academic Press, New York.

17. Jung, M., Weldekidan, T., Schaff, D., Patterson, A., TIngey, S., and Hawk, J. 1994. Generation means analysis and quantitative trait locus mapping of anthracnose stalk rot genes in maize. Theor. Appl. Genet. 89:413-418.

18. Lim, S. M., and White, D. G. 1978. Estimates of heterosis and combining ability for resistance of maize to Colletotrichum graminicola. Phytopathology 68:1336-1342.

19. Mims, C. W., Richardson, E. A., and Taylor, J. 1988. Specimen orientation for transmission electron microscopy of fungal germ tubes and appressoria on artificial membranes and leaf surfaces. Mycologia 80:586-590.

20. Muimba-Kankolongo, A., and Bergstrom, G. C. 1990. Transitory wound predisposition of maize to anthracnose stalk rot. Can J. Plant Pathol. 12:1-10.

21. Muimba-Kankolongo, A., and Bergstrom, G. C. 1992. Wound predisposition of maize to anthracnose stalk rot as affected by internode position and inoculum concentration of Colletotrichum graminicola. Plant Dis. 76:188-195.

22. Nicholson, R. L., and Hammerschmidt, R. 1992. Phenolic compounds and their role in disease resistance. Annu. Rev. Phytopathol. 30:369-389.

23. Nicholson, R. L., and Warren, H. L. 1976. Criteria for evaluation of resistance to maize anthracnose. Phytopathology 66:86-90.

24. Nicholson, R. L., and Warren, H. L. 1981. The issue of races of Colletotrichum graminicola pathogenic to corn. Plant Dis. 65:143-145.

25. Northcote, D. H., Davey, R., and Lay, J. 1989. Use of antisera to localize callose, xylan and arabinogalactan in the cell-plate, primary and secondary walls of plants. Planta 178:353-366.

26. O'Connell, R., Perfect, S., Hughes, B., Carazaniga, R., Bailey, J., and Green, J. 2000. Dissecting the cell biology of Colletotrichum infection process. Pages 57-75 in: Colletotrichum: Host Specificity, Pathology and Host-Pathogen Interaction. D. Prusky, S. Freeman, and M. B. Dickman, eds. The American Phytopathological Society, St. Paul, MN.

27. Perfect, S. E., O'Connell, R. J., Green, E. F., Doering-Saad, C., and Green, R. J. 1998. Expression cloning of a fungal proline-rich glycoprotein specific to the biotrophic interface formed in the Colletotrichumbean interaction. Plant J. 15:273-279.

28. Politis, D. J., and Wheeler, H. 1973. Ultrastructural study of penetration of maize leaves by Colletotrichum graminicola. Physiol. Plant Pathol. 3:465-471

29. Rowley, C. R., and Moran, D. T. 1975. a simple procedure for mounting wrinkle-free sections on formvar-coated slot grids. Ultramicrotomy $1: 151-155$.

30. Sherwood, R. T., and Vance, C. P. 1980. Resistance to fungal penetration in the Gramineae. Phytopathology 70:273-279.

31. Simmons, C. R., Grant, S., Altier, D. J., Dowd, P. F., Crasta, O., Folkerts, O., and Yalpani, N. 2001. Maize rhml resistance to Bipolaris maydis is associated with few differences in pathogenesis-related proteins and global mRNA profiles. Mol. Plant-Microbe Interact. 14:947-954. 
32. Stephenson, S.-A., Hatfield, J., Rusu, A. G., Maclean, D. J., and Manners, J. M. 2000. CgDN3: An essential pathogenicity gene of Colletotrichum gloeosporioides necessary to avert a hypersensitive-like response in the host Stylosanthes guianensis. Mol. Plant-Microbe Interact. 13:929-941.

33. Sweigard, J. A., Carroll, A. M., Farrall, L., Chumley, F. G., and Valent, B. 1998. Magnaporthe grisea pathogenicity genes obtained through insertional mutagenesis. Mol. Plant-Microbe Interact. 11:404-412.

34. Thon, M. R., Nuckles, E. M., Takach, J. E., and Vaillancourt, L. J. 2002. CPR1: A gene encoding a putative signal peptidase that functions in pathogenicity of Colletotrichum graminicola to maize. Mol. PlantMicrobe Interact. 14:120-128.

35. Thon, M. R., Nuckles, E. M., and Vaillancourt, L. J. 2000. Restriction enzyme-mediated integration used to produce pathogenicity mutants of Colletotrichum graminicola. Mol. Plant-Microbe Interact. 12:13561365 .
36. Toman, J., Jr., and White, D. G. 1993. Inheritance of resistance to anthracnose stalk rot of corn. Phytopathology 83:981-986.

37. Vance, C. P., Kirk, T. K., and Sherwood, R. T. 1980. Lignification as a mechanism of disease resistance. Annu. Rev. Phytopathol. 18:259-288.

38. Wattad, C., Kobiler, D., Dinoor, A., and Prusky, D. 1997. Pectate lyase of C. gloeosporioides attacking avocado fruit: cDNA cloning and involvement in pathogenicity. Physiol. Mol. Plant Pathol. 50:197-212.

39. Weldekidan, T., and Hawk, J. A. 1993. Inheritance of anthracnose stalk rot resistance in maize. Maydica 38:189-192.

40. Wharton, P. S., Julian, A. M., and O'Connell, R. J. 2001. Ultrastructure of the infection of Sorghum bicolor by Colletotrichum sublineolum. Phytopathology 91:149-158.

41. Wijesundera, R. L. C., Bailey, J. A., Byrde, R. J. W., and Fielding, A. H. 1989. Cell wall degrading enzymes of Colletotrichum lindemuthianum: Their role in development of bean anthracnose. Physiol. Mol. Plant Pathol. 34:403-413. 